Technical Report

\title{
Nondestructive evaluation of surface degradation of silicon carbide-cordierite ceramics subjected to the erosive wear
}

\author{
M. Posarac-Markovic ${ }^{a}$, Dj. Veljovic ${ }^{b}$, A. Devecerski ${ }^{a}$, B. Matovic ${ }^{a}$, T. Volkov-Husovic ${ }^{\text {b,* }}$ \\ ${ }^{a}$ University of Belgrade, Institute of Nuclear Sciences "Vinca”, P.O. Box 522, 11001 Belgrade, Serbia \\ ${ }^{\mathrm{b}}$ University of Belgrade, Faculty of Technology and Metallurgy, Karnegijeva 4, P.O. Box 3503, Serbia
}

\section{A R T I C L E I N F O}

\section{Article history:}

Received 7 March 2013

Accepted 15 May 2013

Available online 31 May 2013

\begin{abstract}
A B S T R A C T
Covalent bond in SiC ceramic request high temperature for its sintering. In order to put down sintering temperature of $\mathrm{SiC}$ ceramics we choose cordierite as phase between $\mathrm{SiC}$ particles. Reactive sintering is an effective way to produce ceramics at relatively low temperature. We have created in situ $\mathrm{SiC} /$ cordierite composite at $1250^{\circ} \mathrm{C}$. Cordierite precursor was made from commercially available spinel, alumina and quartz.

The possibilities of using silicon carbide-cordierite material as resistant to the erosive wear was goal of this investigation. The fluid dynamic system of the experimental methodology was used here to produce ultrasonic erosive wear. Mass loss and level of degradation were measured before and during the experiment. Level of degradation of the samples was monitored using Image Pro Plus program for image analysis. Average erosion ring diameter as well as average erosion area were monitored during experiment. Obtained results pointed out that after 150 min sample exhibited excellent erosion resistance compared to metal and ceramic samples.
\end{abstract}

(c) 2013 Elsevier Ltd. All rights reserved.

\section{Introduction}

The use of ceramics materials has increased in the last decades within a wide range of applications from electronics to mechanical parts and bio medicine application (hip prosthesis, dental implants). One of the main reasons for that is the improvement of the fracture toughness that allows the ceramic material to perform better when it is subjected to the operating conditions [1-3]. However, there are operating conditions that can produce cavitation erosion on technical ceramics, for example during the operation of bearings, injectors or valves. Hence, the study of the cavitation erosion mechanisms of technical ceramics is of importance to improve their performance in real applications.

Silicon nitride and zirconia as interesting materials with excellent cavitation resistance properties were studied. The erosion mechanism of silicon nitride subjected to cavitation exposure has been studied [3-6]. Previous authors have reported that a larger grain size leads to a larger erosion rate $[4,6]$. The cracking is mainly intergranular although some cracks are visible within big or elongated grains. These cracks produce erosion pits, most of them showing microcracks extension at the boundaries. This produces pits bridging or coalescence, removing successively more pits [7].

\footnotetext{
* Corresponding author. Address: University of Belgrade, Faculty of Technology and Metallurgy, Metallurgical Engineering Department, Karnegijeva 4, 11120 Belgrade, Serbia. Tel.: +381 113370 466, +381 638494 407; fax: +381 113370488 .

E-mail address: tatjana@tmf.bg.ac.rs (T. Volkov-Husovic).
}

Alumina based castable are reported as the ceramics with the promising cavitation erosion resistance in the literature [8-10].

Cavitation, one of the mechanisms of liquid erosion, characterized by the generation and the collapse of vapor structure in liquid, occurs frequently in hydraulic machinery such as pumps, turbine and propellers. The pressure waves emitted during the collapses of vapor structures interact with neighboring solid surfaces, leading to material damage [1-3]. Cavitation damage is often tested for the metallic materials [11-23]. Investigation of influence of the impact load [13] and possibilities of quantitative evaluation of cavitation erosion were investigated [15]. Most of the research were related to the cavitation wear behavior of different types of steels $[16,19-21]$ as well as different types of alloys and coatings $[17,18,23,28,29]$.

The goal of this investigation was to study possibilities of application of silicon carbide-cordierite based ceramic material for potential use as erosion resistant material.

\section{Materials}

Cordierite and silicon carbide are ceramic materials suitable for high temperature application with good chemical resistance. Their target application is in furnaces for use at temperatures over $1000^{\circ} \mathrm{C}$. Typical values of selected properties of dense constituents used in refractory materials investigated are given in Table 1. Cordierite precursor was made from commercially available spinel, alumina and quartz. Starting powder materials were mixed 
Table 1

Typical values of selected properties of dense constituents used in refractory materials investigated $[24,25]$.

\begin{tabular}{lll}
\hline & Cordierite & $\begin{array}{l}\text { Silicon } \\
\text { carbide }\end{array}$ \\
\hline Chemical formula & $2 \mathrm{MgO}^{2}-\mathrm{Al}_{2} \mathrm{O}_{3}-$ & $\mathrm{SiC}$ \\
& $5 \mathrm{SiO}_{2}$ & \\
Density $\left(\mathrm{g} / \mathrm{cm}^{3}\right)$ & 2.60 & 3.1 \\
Modulus of elasticity (GPa) & 70 & 410 \\
Poisson ratio & 0.21 & 0.14 \\
Compressive strength $(\mathrm{MPa})$ & 350 & 4600 \\
Fracture toughness $\left(\mathrm{MPa} \mathrm{m}^{0.5}\right)$ & - & 4.6 \\
Linear thermal expansion coefficient & 1.7 & 3.1 \\
$\quad\left(10^{-6} \mathrm{~K}^{-1}\right)$ & & \\
Hardness (Moss) & 7.5 & 9.5 \\
\hline
\end{tabular}

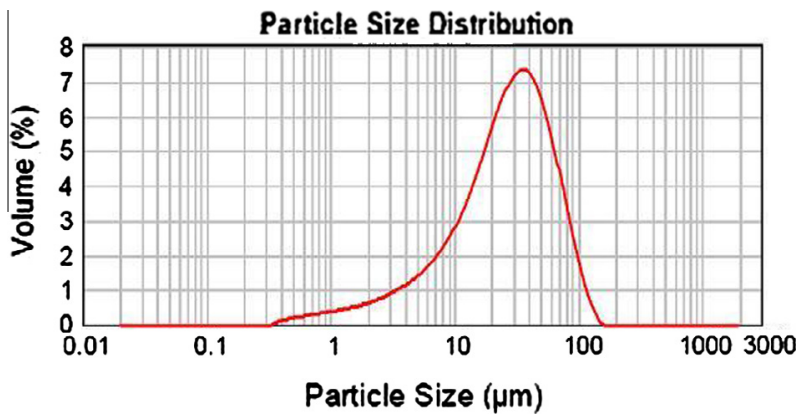

Fig. 1. Particle size distribution of used $\mathrm{SiC}$ powder.

Table 2

Theoretical chemical composition of main crystaline phase in $\mathrm{SiC} /$ cordierite composite.

\begin{tabular}{|c|c|c|c|c|c|c|}
\hline \multirow[t]{2}{*}{ Element } & \multicolumn{2}{|c|}{ Silicon-carbide } & \multicolumn{2}{|c|}{ Cordierite } & \multicolumn{2}{|c|}{ Sapphirine } \\
\hline & at $\%$ & wt $\%$ & at\% & wt $\%$ & at\% & wt\% \\
\hline $\mathrm{Mg}$ & & & 6.89 & 8.31 & 10.29 & 12.33 \\
\hline $\mathrm{Al}$ & & & 13.79 & 18.45 & 26.47 & 35.19 \\
\hline $\mathrm{Si}$ & 50 & 70.05 & 17.24 & 24.01 & 4.41 & 6.11 \\
\hline $\mathrm{O}$ & & & 62.08 & 49.23 & 58.82 & 46.37 \\
\hline $\mathrm{C}$ & 50 & 29.95 & & & & \\
\hline
\end{tabular}

according to the chemical composition of cordierite, $2 \mathrm{MgO} 2 \mathrm{Al}_{2} \mathrm{O}_{3}$ $5 \mathrm{SiO}_{2}$. After attritor milling and drying mixture was used as starting material for obtaining $\mathrm{SiC} /$ cordierite composite ceramics with weight ratio 50:50. Ball milling with $\mathrm{Al}_{2} \mathrm{O}_{3}$ balls in DI water was performed for mixture homogenization. The powder was pressed into cylinders with $2 \mathrm{~cm}$ diameter and approximately $1 \mathrm{~cm}$ high and sintered in air at $1250{ }^{\circ} \mathrm{C}$ for $3 \mathrm{~h}$ with heating rate of $10^{\circ} / \mathrm{min}$.

Particle size distribution was determined with The Mastersizer 2000 particle size analyzer. The Mastersizer 2000 uses the technique of laser diffraction to measure the size of particles. It does this by measuring the intensity of light scattered as a laser beam passes through a dispersed particulate sample. This data is then analyzed to calculate the size of the particles that created the scattering pattern. The SiC powder was dispersed in water. As it could be observed from Fig. 1 particle size of used SiC powder is around $30 \mu \mathrm{m}$. Results for the particle size distribution are given in Fig. 1 .

Results based on XRD and SEM confirmed that structure consists from silicon carbide, cordierite, sapphirine as well as small amount of enstatine. Theoretical chemical composition of main crystaline phase in $\mathrm{SiC} /$ cordierite composite is given in Table 2. Formation of cordierite and sapphirine are influenced by

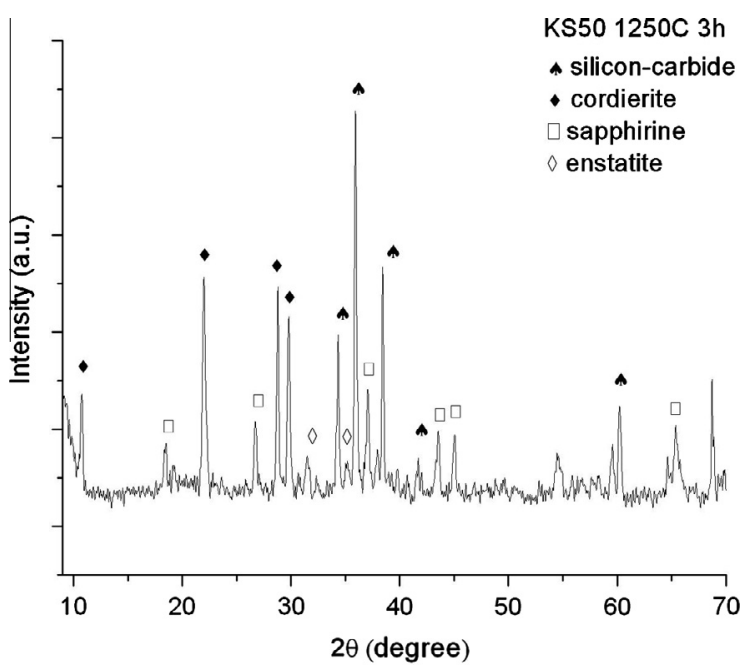

Fig. 2. XRD of the $\mathrm{SiC} /$ cordierite composite ceramics samples.

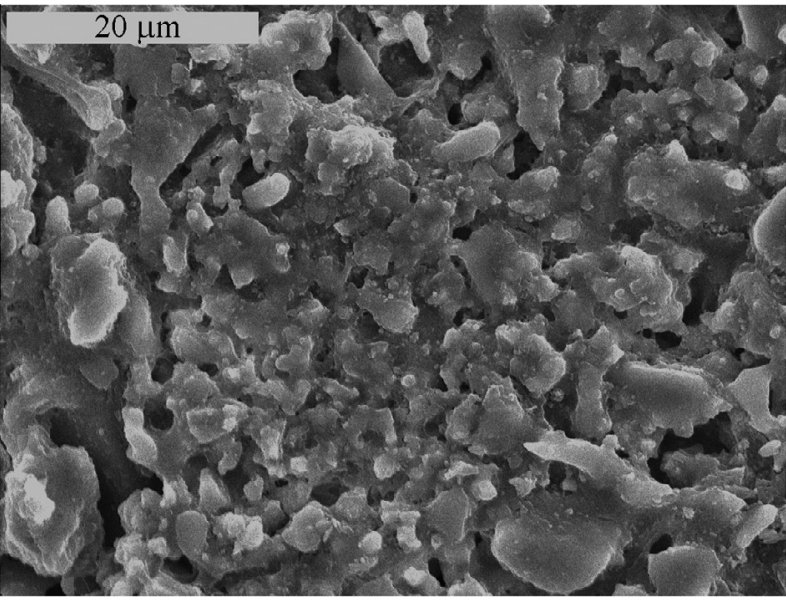

Fig. 3. SEM of the SiC/cordierite composite ceramics sample.

attendance of glassy phase based on $\mathrm{SiO}_{2}$. From SEM micrographs one can see the porous structure of composite ceramics (Figs. 2 and 3$)$.

\section{Cavitation erosion testing}

The fluid dynamic system of the experimental methodology used here to produce ultrasonic cavitation is explained in detail somewhere else [8]. The parameters and geometry of the cavitation erosion test are similar to the equipment described in [7]. Modified vibratory cavitation testing is applied for cavitation erosion determination. Diameter of the horn is $10 \mathrm{~mm}$ and distance between the horn and the sample was $2 \mathrm{~mm}$. Samples were disks with diameter $3 \mathrm{~cm}$.

\section{Results and discussion}

Mass losses of the test specimens were done on an analytical balance with an accuracy of $\pm 0.1 \mathrm{mg}$. The measurements were performed after subjecting each test specimen to cavitation for $30 \mathrm{~min}$. The duration of the tests was $150 \mathrm{~min}$. Optical microscopy technique was applied to analyze the effect of the erosion and to interpret the results of cavitation tests. 


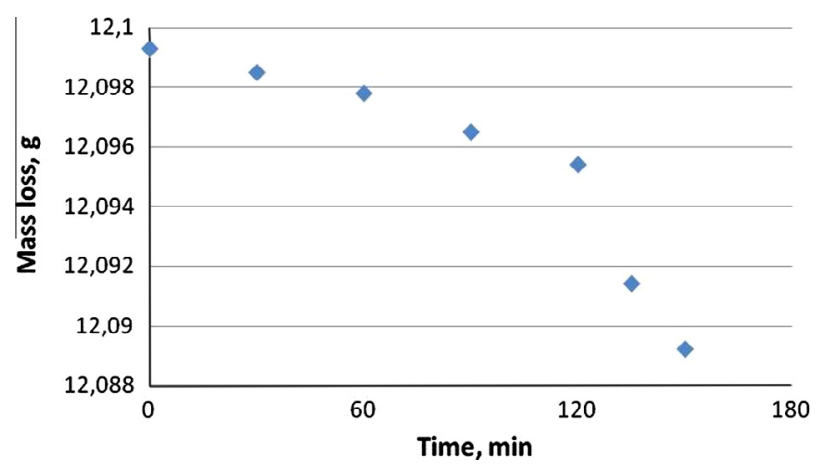

Fig. 4. Mass loss during experiment.

Mass loss after 50 min was $0.0101 \mathrm{~g}$ (Fig. 4). This result could be considered as very good cavitation resistance. Image analysis is useful tool for surface degradation monitoring in different conditions (i.e. thermal shock or durability testing) and obtained very good correlation with mechanical characteristics [7,8,25-27]. In order to monitor the surface degradation, samples were photographed (Fig. 5), and image analysis for surface damage was applied, and obtained results are presented in Fig. 6. Typical cavity at the sample after 150 min of testing is given in Fig. 7.

Erosion rates were chosen similar as for the metallic [9-18] and ceramic [4-6] samples Mass loss during experiment showed the excellent correlation with the time. Image Pro Plus Program was applied for surface analysis during testing. Obtained results showed that surface erosion was in strong correlation with time, and erosion of the sample surface was below $5 \%$ of the surface area before testing (Fig. 7).

Compared to the alumina based samples mass loss was between 1 and $2.6 \mathrm{mg}$, and surface degradation was below 23\% (from the surface $4 \times 4 \mathrm{~cm}$ ) $[5,6]$ samples based on $\mathrm{SiC} /$ cordierite exhibited better resistance to surface erosion.

Based on the XRD and SEM of the samples before testing, it could be mentioned that cordierite is phase more sensitive to the erosive wear, but this sensitivity is still much greater than many

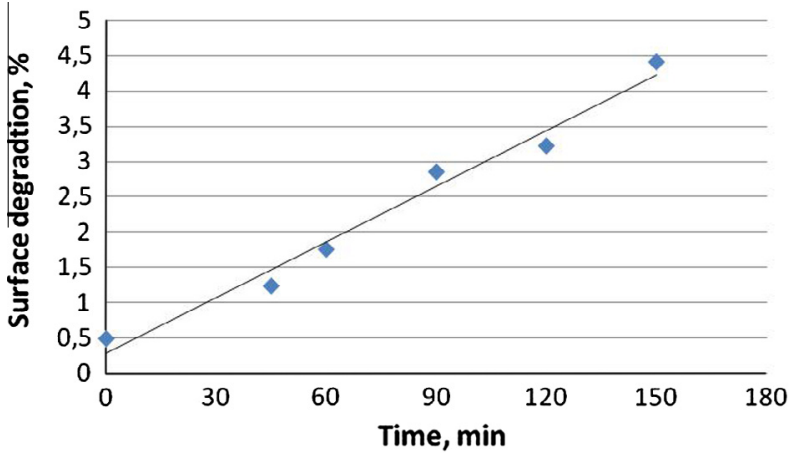

Fig. 6. Level of destruction of the samples $(\mathrm{P} / \mathrm{Po})$ versus time of experiment.

phases in various metallic samples [19-21], as well for some alumina based ceramics $[5,6]$.

Grain size of the investigated samples, as well the morphology could indicate that cavitation erosion resistance will be good. This conclusion could be made according to the well known influence of the grain size to the mechanical characteristics and behavior in different conditions. Smaller grain size could improve mechanical characteristics such are compressive, bending and tensile strength, as well as hardness of the material. As those characteristics are related to the erosion wear resistance, one could expect similar influence to the erosion wear resistance. Smaller grain size, high values of compressive strength and hardness will influence to the better resistance to the erosive wear. As samples were with grain size below $20 \mu \mathrm{m}$, it was expected good cavitation resistance, which was confirmed by obtained results.

The samples exposed to cavitation erosion (Fig. 5) were also monitored in order to measure the diameters and area of the erosion ring region are measured using the following steps:

Step 1: Different micrographs are taken of the eroded part as shown in Fig. 6.

Step 2: At this point two types of measurements are taken: the diameter $\left(d_{1}\right)$ and $\left(d_{2}\right)$ of the cavitation ring erosion measured using Image Pro Plus Program.

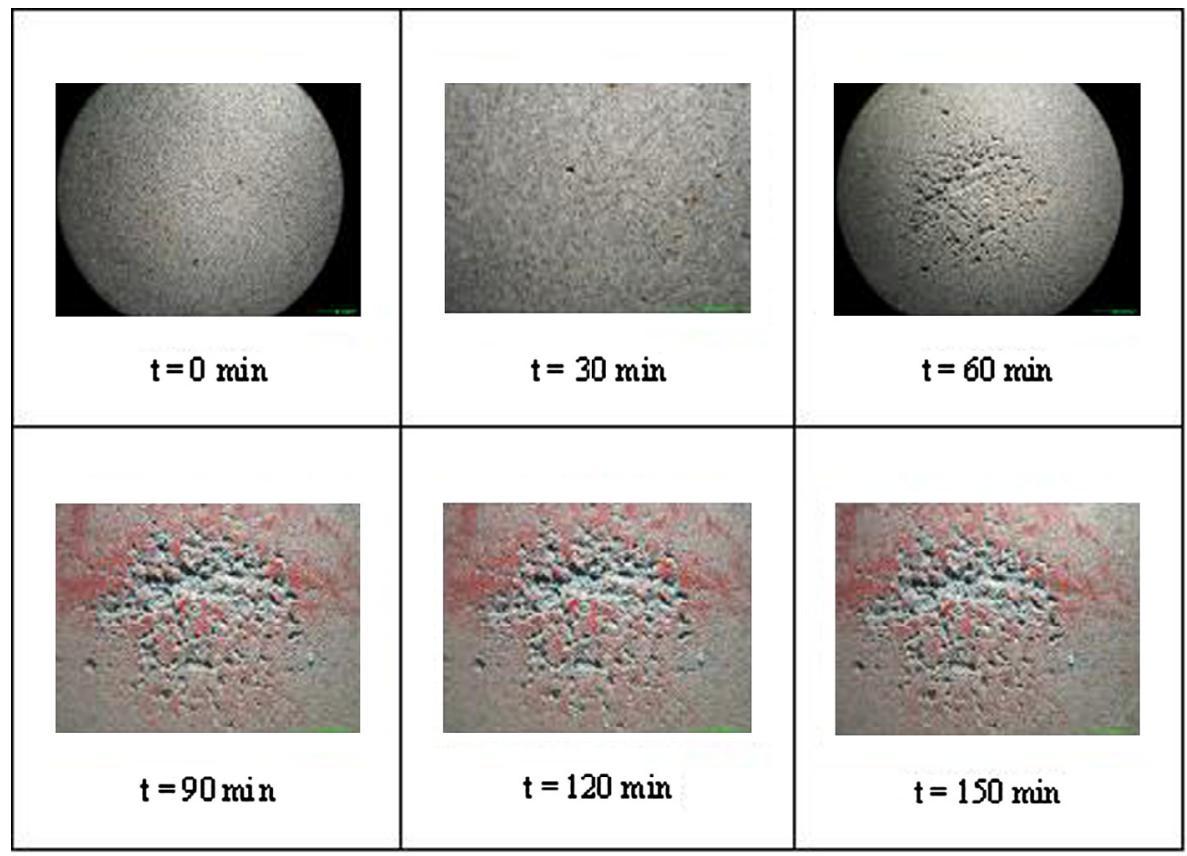

Fig. 5. Samples behavior during testing. 

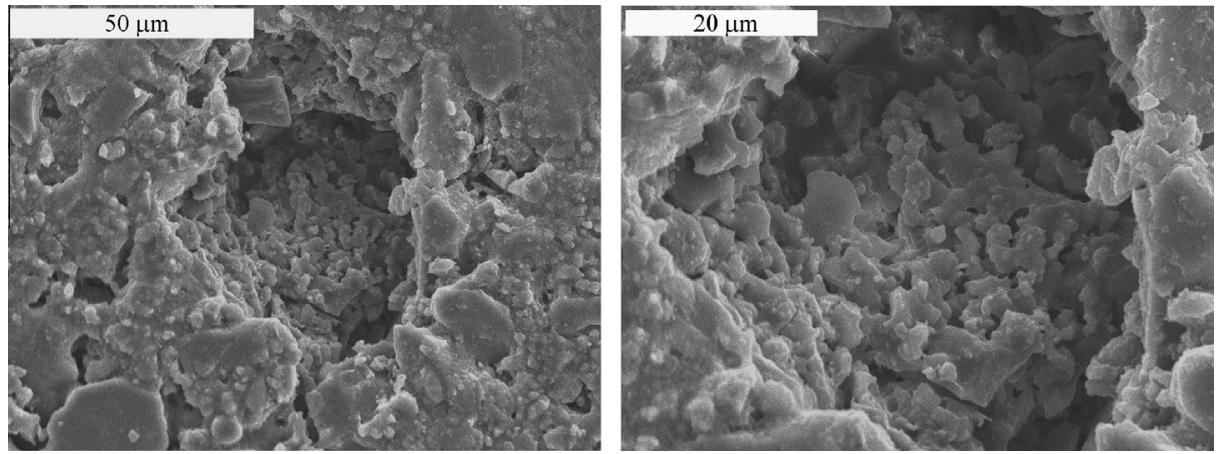

Fig.7. Typical cavity at the sample after 150 min of testing.

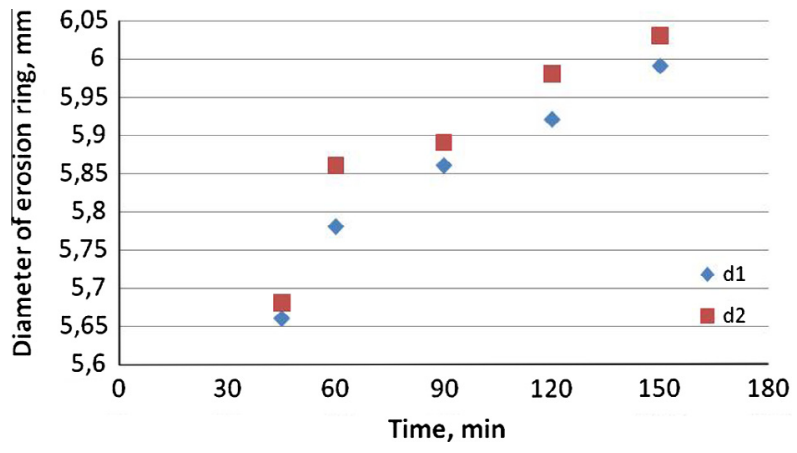

Fig. 8. Average diameter of erosion ring during testing.

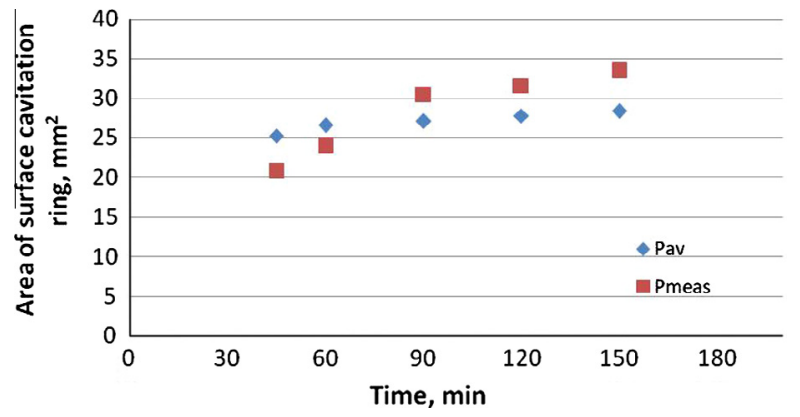

Fig. 9. Average area of the erosion ring based on diameter measurements and area measurements.

Step 3: The effective diameter of each ring is calculated according

$$
d=\frac{d_{1}+d_{2}}{2}
$$

Step 4: The effective area of the erosion ring calculated using

$$
P_{a v}=\frac{\pi d_{1} d_{2}}{4}
$$

Step 5: Average erosion surface area of the ring, measurements using Image Pro Plus Program $\left(P_{\text {meas }}\right)$,

where $d$ is the effective diameter of the cavitation ring region, $d_{1}$ and $d_{2}$ are average values of the diameter of edge of the cavitation ring region measured in different positions.

Measurements for average diameter of erosion ring were taken into account that after 30, 45, 60, 90, 120 and $150 \mathrm{~min}$. Results presented in Fig. 8 pointed out that formation of erosion ring could be observed after $45 \mathrm{~min}$ of testing. Average erosion ring diameter was increasing from $5.66-5.68 \mathrm{~mm}$ after $45 \mathrm{~min}$ to $5.99-6.03 \mathrm{~mm}$ after $150 \mathrm{~min}$ od testing.

Also, obtained results for the average area of the erosion ring are presented in Fig. 9. Both models, based on calculation of the area using Eq. (2). $\left(P_{a v}\right)$ and measurements performed by Image Pro Plus Program gave similar results $\left(P_{\text {meas }}\right)$. Initial area of erosion ring was measured $20.73 \mathrm{~mm}^{2}$ after $45 \mathrm{~min}$, and was increasing to the value of $33.42 \mathrm{~mm}^{2}$ after $150 \mathrm{~min}$.

If Eq. (2) was used for determination of erosion ring area $\left(P_{a v}\right)$, obtained results are very similar to $\left(P_{\text {meas }}\right)$. Results for $\left(P_{\text {meas }}\right)$ gave larger area then $\left(P_{a v}\right)$.

Measurements of direct erosion ring area $\left(P_{\text {meas }}\right)$, using Image Pro Plus Program, could be considered as more accurate.

\section{Conclusions}

The possibilities of using silicon carbide-cordierite material as resistant to the erosive wear was goal of this investigation. The fluid dynamic system of the experimental methodology was used to produce ultrasonic erosive wear.

Cavitation erosion resistance was monitored by:

- Mass loss.

- Average diameter of erosion ring.

- Average area of erosion ring based on calculation of the ring area using measured average diameter and measurements performed using Image Pro Plus Program and

- Monitoring the level of degradation of the sample during erosion testing.

Obtained results pointed out that mass loss was increasing up to $0.0012 \mathrm{~g}$ after $150 \mathrm{~min}$ of testing, as well as average ring diameter which was measures up to $5.7 \mathrm{~mm}$, and erosion ring area was between 20.73 and $33.42 \mathrm{~mm}^{2}$, depending on the used model for erosion ring area determination.

Based on the obtained results it could be concluded that investigated SiC-cordierite composite ceramic could be used in conditions where erosion resistance is expected, as reliable material.

Further investigation with the samples with different SiC content will be performed in order to investigate influence of the phases, as well the morphology of the samples, in order to obtain samples with optimal cavitation erosion resistance.

\section{Acknowledgement}

This research has been financed by the Ministry of Science and Environment of the Republic of Serbia as a part of the Projects III 45012. 


\section{References}

[1] Hammit FG. Cavitation and multiphase flow phenomena. New York: McGrawHill; 1980.

[2] Knapp RT, Daily JW, Hammit FG. Cavitation. New York: McGraw-Hill; 1970.

[3] Tomlinson WJ, Matthews SJ. Cavitation erosion of structural ceramics. Ceram Int 1994;20:201-9.

[4] Litzow U, Gahr K-HZ, Schneider J. Cavitation erosion of advanced ceramics in water. Int J Mater Res: Z Metallkd 2006;97:1372-7.

[5] Niebuhr D. Cavitation erosion behavior of ceramics in aqueous solutions. Wear 2007;263:295-300.

[6] García-Atance Fatjó G, Hadfield M, Tabeshfar K. Pseudoplastic deformation pits on polished ceramics due to cavitation erosion. Ceram Int 2011:37:1919-27.

[7] Martinovic S, Dojcinovic M, Majstorovic J, Devecerski A, Matovic B, Volkov Husovic T. Implementation of image analysis on thermal shock and cavitation resistance testing of refractory concrete. J Eur Ceram Soc 2010;30:3303-9. ISSN 0955-2219.

[8] Martinovic S, Vlahovic M, Dojcinovic M, Volkov-Husovic T, Majstorovic J. Thermomechanical properties and cavitation resistance of a high-alumina low-cement castable. Int J Appl Ceram Technol 2011;8(5):1115-24.

[9] Garćia-Atance Fatjó G, Hadfield M, Vieillard C, Sekulic J. Early stage cavitation erosion within ceramics - an experimental investigation. Ceram Int 2009;35:3301-12.

[10] Garćla-Atance Fatjó G, Torres Pérez A, Hadfield M. Experimental study and analytical model of the cavitation ring region with small diameter ultrasonic horn. Ultrason Sonochem 2011;18:73-9.

[11] Russell RO, Morrow GD. Sonic velocity quality control of steel plant refractories. Am Ceram Soc Bull 1984;63:7:911-914.

[12] Okada T, Iwai Y, Hattory S, Tanimura N. Relation between impact load and the damage produced by cavitation bubble collapse. Wear 1994;184:231.

[13] Hattori S, Mori H, Okada T. Quantitative evaluation of cavitation erosion. J Fluid Eng Trans ASME 1998;120:179.

[14] Okada T, Hattori S. In: Proc. of the international symposium on aerospace and fluid science, Sendai, Japan; 1993. p. 347.

[15] Steller K. In: Proc. of the 6th international conference on erosion by liquid and solid impact, Cambridge, UK; 1983. p. 121.
[16] Bregliozzia G, Di Schinob A, Ahmeda SI-U, Kennyb JM, Haefkea H. Cavitation wear behaviour of austenitic stainless steels with different grain sizes. Wear 2005;258:503-10.

[17] Tomlinson WJ, Bransden AS. Cavitation erosion of laser surface alloyed coatings on Al-12\% Si. Wear 1995;185:59-65.

[18] Lin CJ, He JL. Cavitation erosion behaviour of electroless nickel-plating on AIS] 1045 steel. Wear 2005;259:154-9.

[19] Dojcinovic M, Volkov Husovic T. Cavitation damage of the medium carbon steel: implementation of image analysis. Mater Lett 2008;62:953-6. ISSN 0167-577X.

[20] Dojčinović M, Erić O, Rajnović D, Sidjanin L, Baloš S. The morphology od ductile cast iron surface damaged by cavitation. Metall Mater Eng 2012;18(3):165-76.

[21] Dojčinović M, Marković S. The morphology of cavitation damage of heattreated medium carbon steel. J Serb Chem Soc 2006;71:977-84.

[22] Karimi A et al. Comparison of erosion mechanism in different types of cavitation. Wear 1986;113:305-22.

[23] Trethewey KR et al. Effect of ultrasonically induced cavitation on corrosion behaviour of a copper-manganese-aluminum alloy. Brit. J. Corros. 1988;23:55-60.

[24] http://www.matweb.com/.

[25] Dimitrijevic M, Posarac M, Volkov-Husovic T, Devecerski A, Matovic B. Behavior of silicon carbide/cordierite composite material after cyclic thermal shock. Ceram Int 2009;35(3):1077-81.

[26] Posarac M, Dimitrijevic M, Volkov-Husovic T, Majstorovic J, Matovic B. The ultrasonic and image analysis method for non-destructive quantification of the thermal shock damage in refractory specimens. Mater Des 2009;30:3338-43.

[27] Vlahović M, Savić M, Martinović S, Boljanac T, Volkov-Husović T. Use of image analysis for durability testing of sulfur concrete and Portland cement concrete. Mater Des 2012;34:346-54.

[28] Kot M, Majpr L, Lackner J. The tribological phenomena of a new type of TiN/aC:H multilayer coatings. Mater Des 2013;51:280-6.

[29] Yigezu Belete Sirahbizu, Mahapatra MM, Jha PK. On modeling the abrasive wear characteristics of in situ $\mathrm{Al}-12 \% \mathrm{Si} / \mathrm{TiC}$ composites. Mater Des 2013;50:277-84. 